\title{
AN EXPERT SYSTEM-BASED APPROACH TO PREDICTION OF YEAR-TO-YEAR CLIMATIC VARIATIONS IN THE NORTH ATLANTIC REGION
}

\author{
S.N. RODIONOV* and J.H. MARTIN ${ }^{1}$ \\ Computer Science Department, Engineering Center, ECOT 7-15, University of Colorado, Campus Box 430, Boulder, \\ CO 80309-0430, USA
}

Received 18 November 1997

Revised 25 September 1998

Accepted 25 September 1998

\begin{abstract}
A novel approach to climate forecasting on an interannual time scale is described. The approach is based on concepts and techniques from artificial intelligence and expert systems. The suitability of this approach to climate diagnostics and forecasting problems and its advantages compared with conventional forecasting techniques are discussed. The article highlights some practical aspects of the development of climatic expert systems (CESs) and describes an implementation of such a system for the North Atlantic (CESNA). Particular attention is paid to the content of CESNA's knowledge base and those conditions that make climatic forecasts one to several years in advance possible. A detailed evaluation of the quality of the experimental real-time forecasts made by CESNA for the winters of 1995-1996, 1996-1997 and 1997-1998 are presented. Copyright (C) 1999 Royal Meteorological Society.
\end{abstract}

KEY WORDS: climate forecasting; interannual variations; expert systems; North Atlantic; atmospheric circulation; sea surface temperature; surface air temperature

\section{INTRODUCTION}

An important component of recent research efforts in climatology is the development of methods for determining whether the next year will be warmer or colder than normal, or wetter or dryer than normal. Although climate forecasting on the interannual time scale is still an emerging research area, it is experiencing a rapid transition from theoretical speculation into practice, and some remarkable initial success has already been achieved (Barnston et al., 1994). The possibility of being able to predict mean monthly and seasonal anomalies more than one season in advance was envisioned by Jerome Namias, a pioneer in short-term climate forecasts, who wrote:

'Just as is true for forecasting extremes, I think that there are some hopeful signs on the horizon indicating that forecasts need not be limited to one season in advance. There may be some rhyme and reason to forecasting conditions for an upcoming season and even an individual month, even more than three months in advance. Admittedly, such statements arise from more of a gut feeling than anything else. The forecaster can be trapped by all sorts of 'noise' in the system, but in my opinion the fluctuations are not merely noise.' (Namias, 1985).

Currently, skillful seasonal time-scale predictions are made on a real-time basis for a number of tropical regions around the world. Some methods used for such predictions are based on empirical associations between elements of the general circulation of atmosphere and ocean derived from historical data. Others

\footnotetext{
* Correspondence to: Computer Science Department, University of Colorado, Campus Box 430, Boulder, CO 80309-0430, USA. Tel.: + 1303 4923552; fax: + 1303 4922844; e-mail: sergei@cs.colorado.edu

${ }^{1}$ E-mail: martin@cs.colorado.edu
}

Contract/grant sponsor: National Science Foundation; Contract/grant number: ATM-9320455

Contract/grant sponsor: Mars Company

CCC 0899-8418/99/090951-24\$17.50

Copyright (C) 1999 Royal Meteorological Society 
represent variations of coupled ocean-atmosphere modeling. So far, most of the efforts have been directed toward the prediction of El Niño-Southern Oscillation (ENSO) events in the tropical Pacificthe largest source of interannual climate variability (Kerr, 1992). The Prediction Branch of the Climate Prediction Center (CPC/NOAA) routinely produces ENSO forecasts (with the lead time up to 15 months) using such methods as canonical correlation analysis (Barnston and Ropelewski, 1992), linear inverse modeling (Penland and Magorian, 1993), and the Cane-Zebiak model (Cane et al., 1986; Chen et al., 1995). The results of these forecasts are published by the CPC as Forecast Forum in the Climate Diagnostics Bulletin.

Inspired by successful forecasts of ENSO events, the CPC increased the lead time in their official operational long-lead forecasts of temperature and precipitation over the US up to 1 year. These forecasts (or outlooks) are created using a combination of three tools: (i) canonical correlation analysis (Barnston, 1994), (ii) optimal climate normals (Huang et al., 1996), and (iii) coupled model forecasts (Ji et al., 1994). The results of the outlooks, as well as their components for the first 15 seasons since the long-lead prediction program had been implemented in the middle of December 1994, were discussed by van den Dool et al. (1996). As expected, the forecast skill was highest for the shortest lead, but some positive skill scores were achieved for other lead times up to 12.5 months. It is worth noting that the skill of the operational forecasts is difficult to measure. As discussed by Arkin (1993), not only does it vary with season, location, flow pattern and the state of the ENSO phenomenon, but it is hard to obtain a statistically adequate number of samples because the forecasts are made relatively infrequently.

Experimental forecasts for other regions of the world are also available: surface air temperature (SAT) for Canada (Shabbar and Barnston, 1996) and central England (Colman and Davey, 1997), precipitation for northeast Brazil (Ward and Folland, 1991) and Sahel (Barnston et al., 1996), sea surface temperature (SST) in the northern tropical Atlantic (Penland and Matrosova, 1998) and seasonal hurricane activity in the Atlantic basin (Gray and Sheaffer, 1991; Elsner and Schmertmann, 1993). These and other forecasts can be found in the Experimental Long Lead Forecast Bulletin available over the Internet at http:// www.iges.org/ellfb/. Methods used to produce these forecasts include both the above mentioned ones and others methods, such as multiple regression, discriminant analysis, analog selection procedures and neural networks.

The potential economic benefits of skillful seasonal predictions are enormous, ranging from agriculture to fisheries and from energy sector of economy to water resources management. For example, the potential savings for the agriculture sector in the US may be $\$ 0.5-1.1$ billion over 10 years, even assuming a forecast accuracy of only 60\% (Palmer and Anderson, 1994). A detailed discussion about the use and value of long-range forecasts can be found in Livezey (1990).

Unfortunately, although many important uses exist for predictions of year-to-year variations, and despite the growing belief that such predictions are possible, forecasting skill is currently at a minimal level. This has stimulated scientists to investigate new techniques and approaches to short-term climatic predictions. One of these approaches that differs from current dynamical and statistical methods, is under development at the Computer Science Department, University of Colorado at Boulder. This approach is based on concepts and techniques from artificial intelligence (AI) and expert systems (ES) and has led to the development of the climatic expert system for the North Atlantic (CESNA). This system is designed to predict mean winter climatic characteristics in the region that includes the east coast of North America, the North Atlantic, Europe and European Arctic Seas. The first version of CESNA was completed in 1995 and is described by Rodionov and Martin (1996a). Since then, CESNA has undergone significant modifications including a transition to a newer more sophisticated expert system tool GURU from Micro Data Base Systems, Inc. More significantly, it is being tested for real-time forecasts (so far, three such forecasts for the winters of 1995-1996, 1996-1997 and 1997-1998 have been issued).

The objectives of this article are to describe the principles that CESNA is based on (including a discussion of those aspects of the climate system that lend themselves to knowledge-based AI techniques), to highlight some practical aspects of the development of CESNA, and finally to present a detailed evaluation of the quality of the experimental real-time forecasts made by CESNA. Details about the actual operation of the system, including its reasoning methods and the contents of its knowledge-base can be found in Rodionov and Martin (1996a). 


\section{WHY EXPERT SYSTEMS ARE USEFUL FOR CLIMATIC APPLICATIONS}

The history of research and development in the area of ESs (which is the most practical branch of AI) is rather long. ES techniques have been applied successfully in such diverse fields as medicine, geology, chemistry, physics, engineering, law, manufacturing, process control, computer science and space technology. During the past decade or so there was an active penetration of ESs into environmental sciences (Hushon, 1990; Moninger, 1990; Varis, 1995), including oceanography (Dantzler and Scheerer, 1993), meteorology (Kumar et al., 1994) and climatology (Gopal and Scuderi, 1995). The overall picture that emerges is one of the vigorous activity and rapid growth, with many independent investigations exploring a diversity of ideas. Meteorological ESs address a wide variety of forecasting and diagnostic tasks related to convective storms, precipitation, visibility, clouds and wind. Most of the efforts here are directed toward the development of ESs for weather prediction (operational forecasts), when there is no time to provide a more careful analysis, as in thunderstorm forecasting (Conway, 1989). In this case, an ES simply replaces a human expert, who might not be available at the required time.

Unlike in meteorological forecasts, in climatic forecasts time is less critical. Therefore, climatic ESs take advantage of other aspects of this approach. One of these advantages, that is particularly important in modeling of real-world systems, is the use of symbolic processing rather than numerical operations on sets of data that is typical for conventional programs. The symbolic nature of ESs allows us to represent complex environmental features through so-called feature models, that have become popular in meteorological and oceanographic ESs. As Glenn et al. (1990) have shown, the essential characteristics of complex oceanographic features, such as ocean eddies can be represented in compact form using feature models. Rather than explicitly mapping the characteristics of the feature in detail, the feature model captures the essential eddy characteristics (e.g. shape, size, strength and movement). Similarly, such characteristics of the Icelandic low as its central pressure and geographical position represent integrated information about storm activity in the North Atlantic. In general, feature models serve as an information compression technique that transforms multiple data sets into a single, compact representation, simplifying the tracking and mapping of those features while retaining the essential characteristics.

In CESNA, the climate system is represented as a set of macroclimatic objects or conceptual features, such as centers of action, upper atmospheric ridges and troughs, jet streams, temperature anomalies in key regions, extension of polar ice cover, precipitation patterns, etc. An evolution of the system is described as a sequence of events that involve large-scale interactions between these macroclimatic objects. Understanding and accounting for these interactions is the basis for long-range forecasting. As suggested by Namias (1985), receptivity of the atmosphere to certain types of patterns may extend beyond one season, possibly as far as a year or two in advance because of the slow motions of the oceanic currents. Various positive feedback mechanisms in large-scale ocean-atmosphere interaction also can substantially increase a life-span of climatic anomalies. While these mechanisms are still poorly understood, they often reveal themselves through statistical relationships with a significant time lag. Thus, there is a possibility that if one can account for all of these processes, as well as external factors, such as solar activity, one might be able to make progress even in predicting climatic fluctuations for a year or two ahead.

The ES-based approach to the long-lead forecasts is empirical by nature; it quantifies experience-based expectations and provides estimates of forecast uncertainty. As Gray et al. (1996) point out, the likely superiority of the empirical approach over climate modeling is due to the overly complex nature of the atmosphere-ocean system and the inability of the numerical models to realistically represent this degree of physical complexity. This is a manifestation of a general problem discussed by Zadeh (1987) in his principle of incompatibility. According to this principle, as the complexity of a system increases, our ability to make precise and yet significant statements about its behavior diminishes until a threshold is reached, beyond which precision and significance (or relevance) become almost mutually exclusive characteristics.

Unlike empirical models, the initial value climate models do not utilize explicit knowledge of how the atmosphere-ocean has behaved in the past. They use only current observations and/or variations of current analysis in multiple ensemble predictions. However, most knowledge about the climate system is 
essentially empirical and derived from historical observations and their statistical and phenomenological analyses. Being often vague and uncertain, with elements of contradiction, this knowledge cannot be easily incorporated into the climate models.

What ES designers have discovered (and this does not refer only to climatology), is that informal empirical rules (or rules of thumb) are often more important than the standard theory presented in textbooks and classes. Sometimes these rules augment theoretical knowledge; occasionally they are simply shortcuts that seem unrelated to the theory but have been shown to work (Luger and Stubblefield, 1993).

The problem is that the amount of empirical climatic information is increasingly so large that it becomes difficult for a scientist to keep track of it all. In the case of long-term predictions, this information can not be limited by the target area of the forecast. Due to teleconnections, it is necessary to collect information from virtually all over the world. In this situation, the organization of information, along with reconciliation and connection of evidence and ideas, plays a very important role. CESs can help deal with an overload of data, by translating information into usable knowledge. Experience shows that they are excellent organizational tools that provide guidance to the users and facilitate their access to relevant information.

One of the elements of intelligent forecasting system is its ability to explain why the conclusion was made and how certain it is. This feature has a high utility in climatology, where different estimates of the state of macroclimatic objects may have significantly different kinds of information supporting them. In a knowledge-based system, this explanation can be done only within the context of the knowledge base, but as will be seen later, the knowledge base can be easily updated to reflect new findings about the climate system and its behavior. What is important here is that a description of this knowledge is given in the language that is close to our own conversational language. Therefore, no interpretation of complex mathematical constructions is required, so the knowledge remains explicit to the user.

It should be noted that ESs come in two basic varieties: (i) diagnostic, where the system is given a set of competing hypotheses and some evidence concerning their relative likelihood and is asked to rank the hypotheses, and (ii) forecasting, where the system is given values of observed variables, a specific target variable and a point in the future, and is asked what value will the target variable assume. CESNA is, obviously, a forecasting rather than a diagnosing system. However, there is an element of diagnosis in CESNA too: when one makes 'predictions' for the past years, one can determine what factors have caused the anomalies in the year of forecast. These exercises help us better understand and link together seemingly unrelated events in the climate history of the 20th century.

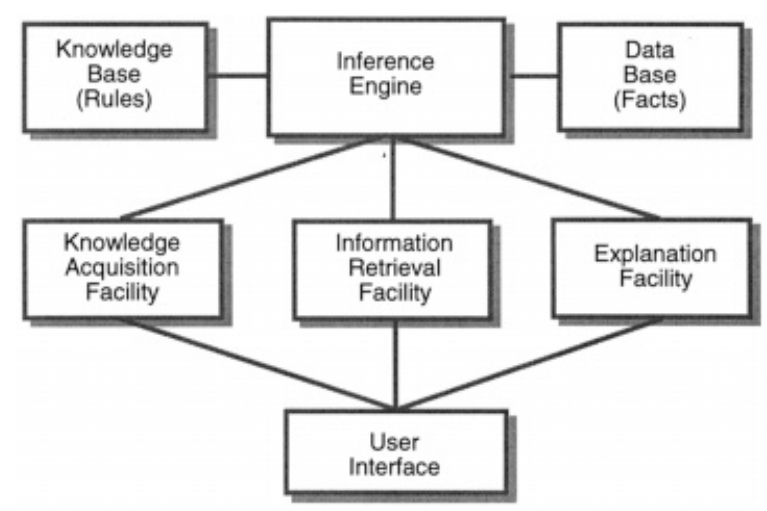

Figure 1. Principal structure of CESNA 


\section{BASIC STRUCTURE OF CESNA}

The principal difference between an ES and a conventional program lies in its structure. Figure 1 illustrates the structure of CESNA, which is quite similar to that of a typical ES and consists of six major modules: (i) knowledge base, (ii) inference engine, (iii) knowledge acquisition facility, (iv) database, (v) information retrieval facility, and (vi) explanation facility.

\subsection{Knowledge base}

CESNA's knowledge of the climate is stored in the knowledge base. Unlike conventional programming, where the knowledge is represented implicitly within the structure of a program, the knowledge base in ESs is explicitly separated from the control module, or inference engine. This makes it much easier to add new knowledge either during program development or in the light of experience during the program's lifetime. This incremental updating of the knowledge base can be done relatively easily; this is particularly important for such dynamically developing sciences as climatology, where the perception of different climatic processes and the mechanisms of their interaction changes very quickly.

In CESNA, the knowledge is encoded in the form of symbolic IF-THEN rules, which is the standard form of knowledge presentation in expert systems. For example, a rule linking central pressure of the Icelandic low and mean winter temperature in northwest Europe can be written as follows:

IF Icelandic $\_$low $=$deep

THEN northwest_Europe $=$ warm, $\quad \mathrm{CF}=80$.

Here, CF refers to a confidence factor that represents a numerical measure of confidence in the validity of the rule. It varies from 0 (no confidence at all) to 100 (complete confidence).

Most of the rules in CESNA have been derived directly from the climate literature, rather than from interviews and behavioral analyses of expert forecasters, which is typical for many other ESs. In fact, results found in research articles can often be easily codified as one or several IF-THEN rules. The published basis for these rules, such as descriptions of field experiments, algebraic manipulations and statistical analyses serve to convince the reader that the result is scientifically correct. The degree of belief in a given result can be expressed as a confidence factor associated with the rule.

\subsection{Inference engine}

The inference engine is the part of an ES that has the ability to reason with a knowledge base of rules. It determines what 'reasoning' strategy is used and how the uncertainty is processed. The inference engine is, in effect, the intelligence that allows the ES to make conclusions based on the 'expertise' or 'knowledge' relevant to the problem domain. CESNA's inference engine uses the standard ES techniques of chaining (both forward and backward), along with sequential and parallel combination of confidence factors. Full details of CESNA's inference engine can be found in Rodionov and Martin (1996a). Briefly, forward chaining occurs when the conclusion (or THEN part) of one rule matches the input to another rule an so on. In this way, evidence can propagate through the knowledge base to allow conclusions to be drawn that are not directly related to the evidence by a single rule. Backward chaining works in a similar fashion from conclusions to causes. CESNA manages the uncertainty associated with these conclusions through the use of MYCIN-style certainty factors (Buchanan and Shortliffe, 1984), a variant of a naive Bayes interpretation of certainty factors as probabilities.

\subsection{Knowledge acquisition facility}

Whether through an interview with scientists or through an intensive literature search, the transformation of human knowledge into an ES is a very time consuming and labor intensive task, and is often considered as the bottleneck in ES development. In recent years, however, a broad range of statistical tools based on machine-learning techniques have emerged. These tools perform what is called 'data 
mining' - an extraction of hidden information from large databases (Mena, 1996). Their strength is in their ability to discover trends and patterns in data and identify key relationships between variables.

The knowledge acquisition facility in CESNA is a separate module that belongs to this class of rule induction programs or decision tree generators. It is written in FORTRAN and works with a data set presented in the form of a matrix $\boldsymbol{M}$ of $N$ by $(m+1)$ dimensions:

$$
\boldsymbol{M}=\{\boldsymbol{X}, \phi\}=\left(x_{1}, x_{2}, \ldots, x_{m} ; \phi\right)_{t,} \quad t=1,2, \ldots, N .
$$

Here, the elements of vector $\boldsymbol{X}_{t}=\left\{x_{i}\right\}_{t}, i=1,2, \ldots, m$ are values of macroclimatic variables that describe the state of the climate system at the time $t ; \phi$ is the value of a 'dependent variable'; $N$ is the number of time steps in the dataset, or the size of the archive. The range of variations of the dependent variable is divided into $K$ classes, so that

$$
\phi_{k}=(\phi=k), \quad k=1,2, \ldots, K .
$$

In the simplest case, when there are only two classes, e.g. 'above normal' and 'below normal', $\phi_{k}$ becomes a dichotomous variable. All independent variables are also divided into classes, the number of which may vary from variable to variable.

To determine the relationship that links the dependent variable with a combination of independent variables the program utilizes the principal of successive addition of variables in accordance with their expected usefulness. A usefulness $(U)$ of a parameter $A$ may be expressed as the difference between conditional probabilities:

$$
U=P(A \mid \phi)-P(A \mid \bar{\phi}),
$$

where $P(A \mid \phi)$ is the probability that the parameter $A$ (the class of a variable in this case) will be observed if $\phi$ is also observed, and $P(A \mid \bar{\phi})$ is the probability of $A$ to be observed in any other cases. The program finds the variable and its value (class) for which $U$ is maximum and, depending on whether or not this variable had this value at time $t$, divides matrix $\boldsymbol{M}$ into two submatrices for which the same calculations are performed. As a result, the program generates a decision (or linkage) tree that represents a graphical form of IF-THEN rules. This program was successfully applied to determine the relationship between changes in water level of the Caspian Sea and large-scale climatic processes in the Northern Hemisphere (Rodionov, 1994), and the authors are planning to widely use it at subsequent stages of CESNA development.

\subsection{Database}

In addition to its knowledge base of rules, CESNA has a database that contains fairly static, simple descriptive facts about the climate system, e.g. that winter of 1977 was cold in the south-eastern US. Some of these data were put in the data base at the initial phase of the system development, others were added through consultative dialog between the ES and the user or through the inference of the ES itself.

These data are presented as fuzzy sets (Zadeh, 1965). In bivalent or two-valued logic, where true and false are the only possibilities, an object is either in a set or not in a set. The degree of membership in a fuzzy set is measured by the membership function defined as

$$
\mu_{A}(x): X \rightarrow[0,1] .
$$

The membership function maps $X$ into the codomain of real numbers defined in the interval from 0 to 1 inclusive and symbolized by $[0,1]$. That is, the membership function is a real number

$$
0 \leq \mu_{A} \leq 1,
$$

where 0 means no membership and 1 means full membership in the set. A particular value of the membership function, such as 0.5 , is called a grade of membership.

To illustrate the concept of fuzzy sets, consider a statement 'winter is cold'. A crisp set description requires an arbitrary decision as to what constitutes cold winter. Is it one when mean winter temperature 


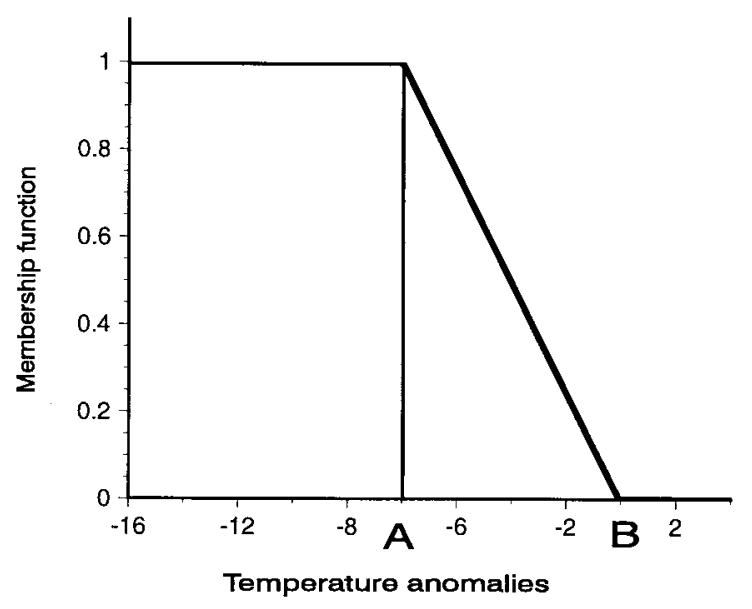

Figure 2. A membership function for the fuzzy set 'cold winter'

drops below 5,10 or $20^{\circ} \mathrm{C}$ ? There are winters when everybody agrees that it is cold and there are winters that one cannot be so certain. Figure 2 shows one possible membership function for 'cold winter'. If temperature drops below the point marked as $\mathrm{A}$, then the membership function equals 1 , i.e. there is a consensus that the winter is cold. If temperature rises above point $\mathrm{B}$, then there is no one who would call the winter cold. And, finally, when temperature is between A and B, the opinion is mixed. In CESNA, if the direct measurements are available, point A coincides with the standard deviation of temperature, point $\mathrm{B}$ is its long-term mean or normal value, and between $\mathrm{A}$ and $\mathrm{B}$ the value of the membership function is determined by a linear interpolation.

In reality, however, the situation is somewhat more complex. For example, there are different indices that measure the strength of the westerly winds over the North Atlantic, and the membership function may vary depending on which index is used. Moreover, one may not have direct measurements for some climatic variables and use indirect or proxy data to characterize them. This brings an additional element of uncertainty regarding statements about these variables. Therefore, the grades of membership for the data are interpreted as confidence factors that reflect not only their deviation from normal but how certain the information about them is.

\subsection{Information retrieval facility}

The information retrieval facility is used to reduce uncertainty related to climatic data and to help the user answer the questions the system asks during the consultation. It contains two submodules, 'Climate of the Year' and 'Historical Time Series', that represent different slices of climatic information. The first submodule provides information (both textual and graphical) about characteristic features of a climatic situation in each year or a period of years if those years have something in common. Typically, this information consists of different maps of spatial distributions of meteorological and oceanographic variables, descriptions of anomalous events in different parts of the globe, tropical and extratropical highlights, etc. The second submodule allows the user to retrieve historical time series of various climatic variables, along with analyses of their interannual variations. When the system asks the user a question, it brings all the relevant information to facilitate the answer. This directed provision of information is very effective, because the user starts reading all these lengthy and tedious climatic descriptions with a different attitude, so that many details hardly noticeable before become significant. Other information becomes important when needed. 


\subsection{Explanation facility}

The last module in Figure 2 is the explanation facility that provides the user with a history of each consultation giving a step-by-step explanation of the reasoning process for the given forecast. During the consultation, CESNA records the path of the inference engine and stores it in a file. This file represents a report containing references to all the rules that were used during the consultation, preliminary results for each rule set, and the final result. Having this report, the user can clearly see the logic of the reasoning. In contrast, conventional programs require the user to trust the program or programmer that the result produced by the program is correct.

\section{CESNA'S KNOWLEDGE BASE: WHAT MAKES THE CLIMATIC FORECAST POSSIBLE?}

Currently, CESNA's knowledge base contains more than 400 empirical climatic rules. For practical reasons, they are conditionally divided into separate sets such as 'Solar activity', 'Global characteristics', 'ENSO', 'Time series', 'Lag relationships', 'North Pacific' and 'North Atlantic'. These sets were described in the authors' previous work (Rodionov and Martin, 1996a). Here, focus will be on a question: what is there in these rule sets that makes climatic forecasts possible?

There is a growing belief that monthly and seasonal time averages of climatic variables can be predicted with sufficient skill to be beneficial for social and economic applications, even though the details of the day-to-day weather cannot be predicted beyond a few weeks (Shukla, 1993). If we look at the daily synoptic maps for the North Atlantic, for example, we will see that the behavior of the atmosphere looks very chaotic, with storms moving in seemingly random fashion. Obviously, it is impossible to foresee a season or even a month in advance where a particular storm will be generated and what would be its trajectory. It is not impossible, however, to predict with a year or longer time lead that Atlantic storms will predominantly be shifted to the north or south of their normal trajectories and thus have a significant impact on seasonal temperature anomalies in Europe. This belief rests primarily on the assumption that there is a deterministic element in the low frequency variability of climatic variables and large-scale interactions between them. As Namias and Cayan (1981) wrote: 'Although it is small-scale processes that govern the details of air-sea interactions, it is certainly the large-scale phenomena that ultimately drive the temporally and spatially averaged exchanges of heat, momentum, and water vapor.'

The major task in any empirical forecasting method is to find and utilize those relationships between different members of the macroscale climatic system that have a significant time lag. Unfortunately, many currently known statistical links between climatic variables are practically simultaneous and thus do not have direct forecasting value. In some cases, however, the time lag is significant enough to be of practical use. Thus, Namias (1976) and Davis (1978) found statistically significant relationships between the strength and position of the Aleutian low in autumn and winter and midlatitude Pacific SST anomalies during preceding seasons. Douglas et al. (1982) have shown that SST anomalies averaged over larger areas exhibit low frequency signals that might provide a basis for explaining recurrent climatic anomalies occurring in groups of winters. In the North Atlantic, Deser and Blackmon (1993) established a link between winter sea ice concentration anomalies in the Davis Strait/Labrador Sea region and a time series of the second EOF of winter (November-March) SST. The latter is characterized by a dipole pattern with anomalies of one sign east of Newfoundland, and anomalies of the opposite polarity off the southeast of the US. If the two time series are superimposed, the maxima in sea ice concentration precede the maxima in SST by 1-2 years. The correlation between the two time series is -0.26 at 0 lag; -0.62 when sea ice leads SST by 1 year; -0.76 when sea ice leads by 2 years; and -0.62 when sea ice leads by 3 years. The strong lag correlations indicate that winters of heavy sea ice in the Labrador Sea precede winters of colder than normal SSTs east of Newfoundland. It is plausible that sea ice anomalies in the Labrador Sea are advected southeastward, resulting in colder than normal SSTs east of Newfoundland the following (or second) year. 
As the last example shows, in many cases a time lag is caused by a slow motion of major oceanic currents. Another good example in the case is a trans-Pacific movement of SST anomalies described by Favorite and McLain (1973). They have shown that it takes about 2-3 years for the anomalies to cross the ocean from Japan to North America. Temperature and salinity anomalies imbedded in oceanic currents can stay there for surprisingly long periods of time. Thus, Dickson (1988) has traced the 'Great Salinity Anomaly' that travelled along the subpolar gyre from 1968 until 1982. To withstand dissipation of these anomalies some other processes associated with ocean-atmosphere interaction should also be involved. Namias (1972) has demonstrated how this interaction can work in the North Pacific to propagate SST anomalies northeastward on the time scale of seasons.

The large-scale interaction between macroclimatic variables is inherently complex and involves various negative and positive feedback loops. Through negative feedbacks, the climate system tries to suppress an anomaly and return the system to normal conditions. Sometimes, the reaction of the system may be too strong, so that a sign of anomaly may change into an opposite one and instead of a gradual decrease of an anomaly one may see some sort of oscillations in this climatic variable. In the positive feedback loop, a climatic anomaly once occurred is maintained for a long time or even tends to increase. One of these positive feedback loops was described by Semenyuk (1984), who noted that if a negative SAT anomaly is formed in the north-western Atlantic, the probability of its replacement by a positive anomaly within the subsequent year is almost negligible. The mechanism responsible for this persistence is as follows (Figure 3). Induced by the advection of cold Arctic air, negative SAT anomalies in the north-western Atlantic are associated with the positive phase of the NAO, when the Icelandic low is deeper than normal. This phase of the NAO is also characterized by an intensification of both the Gulf Stream and the Labrador current. As a result of this intensification, thermal contrasts in the oceanic Polar frontal zone are sharpened. Boosted SST gradients transferring to the atmosphere promote cyclonic activity along the front and intensification of the Icelandic low. The latter, in turn, leads to further advection of cold air masses into the north-western Atlantic, and hence, maintenance of the negative temperature anomalies in this region.

A significant portion of the rules in CESNA are devoted to the effect of ENSO on the Northern Hemisphere extratropics. Despite the modest strength of its simultaneous correlation with the extratropical circulation, the El Niño signal is appealing as a predictor of extratropical climate anomalies because of the observed lag correlations between SST anomalies in the eastern equatorial Pacific during the middle months of the year and Northern Hemisphere circulation anomalies during the following winter. Wallace and Jiang (1992) argue that these correlations are far stronger than any potential predictive relationships

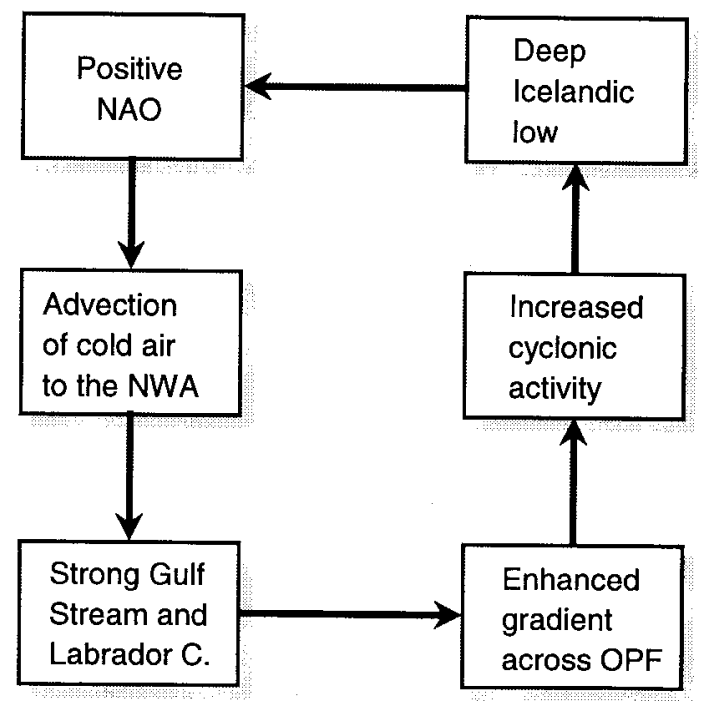

Figure 3. The Semenyuk (1984) conceptual model 
involving extratropical SST that have yet been identified. These relatively strong lag correlations are a consequence of the remarkable stability of the SST pattern in the El Niño region during the interval between the middle months of the calendar year and the end of the year. In order to extend the lead time for the forecast beyond several months, we need to use the forecast of ENSO itself. These forecasts are issued by the Climate Prediction Center on a regular basis. In addition to these forecasts, CESNA makes use of some precursors of ENSO events. Kiladis and Diaz (1989), for instance, computed composite maps of SAT, SST and precipitation anomalies during various stages of an event in the ENSO for several hundred stations around the globe. A comparison of these patterns with the observed spatial distributions of these anomalies may shed some light to what ENSO event, warm or cold, is in progress.

Other factors, such as solar activity, are also taken into account. As Mendoza et al. (1991) have shown, El Niño events tend to occur around sunspot minima and small negative gradients at the decreasing branch of the solar cycle. During the period they analyzed (1700-1985), more El Niños (63\%) occurred in sunspot minima or with negative gradients of the solar cycle, than in maxima or in the increasing branch (37\%). Of course, based on this rule, one cannot predict whether or not an ENSO event will occur next year, but our certainty will be somewhat biased toward an El Niño or La Nina depending on the phase of the solar cycle.

There are also some other rules in the knowledge base that describe the effect of solar activity on the westerlies in the middle latitudes, temperature in central Europe, sea ice in the North Atlantic, and other climatic variables. The mechanism of the solar influence on the Earth climate is still unknown while some interesting hypotheses exist (Bucha, 1991). Therefore, these rules are used with various but usually small confidence factors to reflect this situation.

The use of solar activity in climate predictions on the interannual time scale is very much simplified by the fact that the 11-year sunspot cycle is surprisingly stable, so that it is quite easy to predict where it will be one or several years in advance. Climatic cycles, on the contrary, are much less stable over time and can easily change their amplitude, period or phase. Cycles with periods of 2,3,4 or more years have been found in many climatic variables and were heavily exploited in numerous prediction schemes, especially in the 1960s and 1970s. Unfortunately, most of these cycles usually disappear soon after they had been reliably established (Burroughs, 1992), and later the popularity of those methods diminished. We should not however, be too quick to either accept or reject these cycles. As Mann et al. (1995) point out, such events where the oscillation is interrupted (or phase information is lost) are nevertheless spatially coherent, suggesting that the observed behavior may indeed be real, and reflective of the non-linear dynamics of the overall system.

The best established periodicity for frequencies lower than one cycle per year appears to be the regular reversal of the winds in the stratosphere over the Equator with a period about 28 months. This period was also found in many other climatic variables, e.g. SAT in the contiguous US (Rasmusson et al., 1981) and central Europe (Lamb, 1972), SST in the North Atlantic (Seryakov, 1979), SLP in the 'centers of action' (Angell et al., 1969; Trenberth and Shin, 1984), the NAO (van Loon and Rogers, 1978) and ENSO (Alexander and Weickmann, 1995) indices. In spite of the ubiquity of the quasi-biennial oscillation (QBO) in surface weather records, there is no adequate physical explanation as to how the QBO in the stratosphere is linked with all the fluctuations of similar duration. There are, however, empirical forecasting rules supported by high statistical correlations that allow the use of information on QBO to estimate atmospheric circulation and temperature patterns in the lower troposphere. For example, during the eastern phase of equatorial stratospheric winds, frequency of tropical storms is low (Gray and Sheaffer, 1991). As shown by Labitzke and van Loon (1988), stratospheric QBO can also modulate the effect of variation in solar activity. A combination of the 11-year cycle in sunspot numbers and QBO is used as one way to evaluate cyclonic activity in the North Atlantic, latitudinal position of storm tracks, and winter temperature in the southeast US (Labitzke and van Loon, 1993).

Quite often climatic cycles can be asymmetric, with phases of different longevity. For example, one of the basic features of iceberg number variability in the northwest Atlantic is a tendency for high annual iceberg numbers to occur in groups of 3 or 4 consecutive years, with local minimum counts tending to occur at intervals of 4-9 years (Marko et al., 1994). CESNA can easily utilize even irregular cycles such as El Niño, whose period varies from 2 to 7 years. This rule may look like: 
IF time_passed_since_previous_El_Niño=long

THEN El_Niño_event, $\mathrm{CF}=4$.

This rule may be combined with the rule that describes a relationship between solar activity and the intervals between successive El Niños found by Enfield and Cid (1991). They showed that when solar activity is high, strong El Niños occur farther apart then when solar activity is low. A low level of solar activity is supposed to leave the El Niños free to develop at intervals near 2-3 years, the recurrence interval favored by the internal dynamics of the southern oscillation system.

Some climatic variables demonstrate fluctuations in the form of abrupt transition from one relatively stable regime of fluctuations to another. Thus, Dickson and Namias (1976) noted an existence of climatic regimes on the order of about 10 years in surface air temperature fluctuations in the south-eastern US. These climate regimes have much in common with those in the Barents Sea (Rodionov and Krovnin, 1992) and the Bering Sea (Rodionov and Krovnin, 1991). Little is known about these regimes and it is very difficult to make predictions during periods of regime transition. However, if the regime is established, it is possible to assume (taking into account the average life span of those regimes) that it will not change in the nearest year(s). The confidence factor in this case will reflect the likelihood of maintenance of the current regime, i.e. how long the current climate regime will continue until it will be replaced by a new one. Decadal climate regimes (background memory) are now part of the Climate Prediction Center's effort in seasonal forecasting.

As one can see, CESNA tries to use every possible means-cross-correlations between climatic variables with a significant time lag, effects of external factors, such as solar activity, precursors, cycles and other regularities in historical time series, forecasts prepared by other parties - to find bits of information about what climatic situation in the year of forecast might be. This information may be very scattered, but due to the teleconnections, much of it can be utilized. Then, using rules that describe contemporaneous relations between macroclimatic variables, CESNA combines these various pieces of evidence to produce the final forecast for the target variable in a given region.

\section{SOME ASPECTS OF WORKING WITH CESNA}

The current version of the system is designed to predict winter climate. Winter was chosen for several reasons. Firstly, there are simply much more studies made for the winter climate than for any other season, and it was easier to collect rules for this system. Secondly, many oscillation patterns, such as the NAO and the North Pacific oscillation (NPO), manifest themselves in winter, while during the warm period they either weaken or disappear completely (Barnston and Livezey, 1987). The effect of ENSO on the extratropics is also most prominent in the winter season (Wallace and Jiang, 1992). And thirdly, winter is a period of strongest pressure gradients and greatest interannual variability in the North Atlantic sector (Lamb, 1972; Tucker and Barry, 1984), and it was a real challenge to test the system for this season. If a forecast is known for winter months, one can also judge about the year in general, since mean winter and annual characteristics are often strongly correlated.

CESNA begins a consultation session by asking the user for the year for which a prediction is going to be made. Currently, a lead time of the forecasts is about 9 months. They are usually made in spring when the information about the past winter becomes available and can be used to predict next winter. CESNA then systematically processes the rules in the rule sets and combines confidence factors to create a scenario for the forthcoming winter. To illustrate a forecasting process, consider a fragment of the ENSO rule set presented in Figure 4. In this figure, year 0 is the year when the forecast is to be made. Since in early spring of this year it is not known whether it will be a year of El Niño or La Nina, this needs to be determined first. ENSO event is the goal variable in this rule set and, using backward chaining as described in Section 3, CESNA tries to find its value along with the confidence factor. To do this, CESNA asks the user to compare global SAT distribution in the winter of year 0 and preceding seasons with the typical SAT distributions before El Niño event. It also uses ENSO forecast prepared by the 


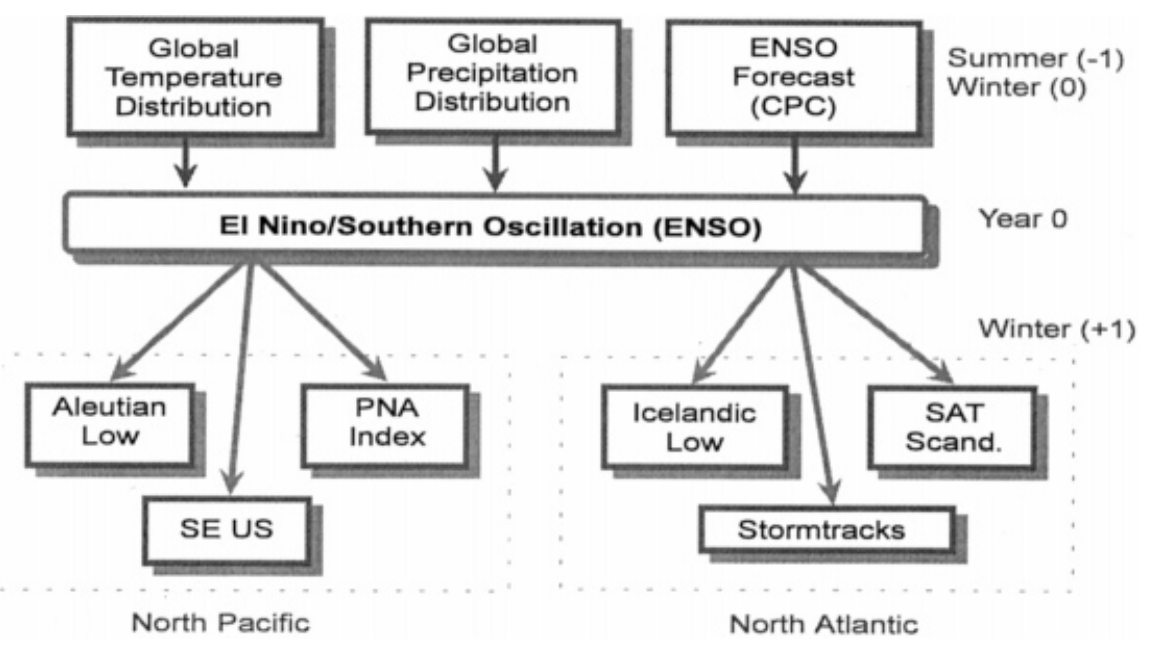

Figure 4. ENSO knowledge base (fragment)

Climate Prediction Center. In CESNA, it is written simply as a rule: $\boldsymbol{I F} C P C_{-}$forecast $\mathrm{I}_{-} \mathrm{Niño}$, THEN El_Niño, allowing the user to decide what confidence factor to assign to the CPC forecast. As soon as the ENSO event and its CF are determined, CESNA uses forward chaining to calculate possible consequences of that both for the North Pacific and North Atlantic. When the consultation session comes to the last 'North Atlantic' set of rules, CESNA asks the user to specify the climatic variables and region that they are interested in, and comes up with the final assessment of this variable.

The range of variations of almost all variables in CESNA is divided into two classes, basically, above normal and below normal. This means that each rule consists of two subrules that are symmetric to each other. For example, the relationship between Greenland blocking index and sea ice conditions in the Davis Strait/Labrador Sea area (Zhifang and Wallace, 1993) is written as follows:

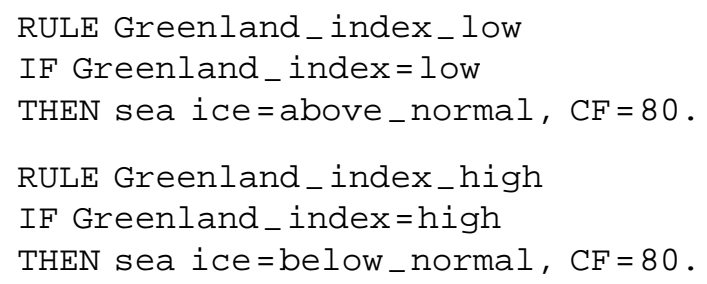

This simplification is justified by the fact that most of the climate anomalies in the North Atlantic region are opposite to each other during two extreme phases of the North Atlantic Oscillation (van Loon and Rogers, 1978). The same is true with respect to the Southern Oscillation. Kiladis and Diaz (1989) found that regions of large, statistically significant signals during warm ENSO events were characterized by equally large signals of the opposite sign during cold events. Essentially the same results were obtained by Bradley et al. (1987), Kiladis and van Loon (1988) and Ropelewski and Halpert (1989) in their analyses of temperature and precipitation during warm and cold events. The implication is that the global climate system tends towards two approximately inverse states with respect to both the NAO and SO.

One of the most difficult problems encountered in constructing the knowledge base is assigning confidence factors to the rules. Most of the rules in CESNA are based on information that comes from empirical studies, which provide a large body of circumstantial evidence about the climate system. Many of these works are case studies involving a combination of synoptic, statistical and conceptual physical reasoning. If enough quantitative data are available, CFs are closely linked with the correlation coefficient or another measure of the strength of relationship between the climatic variables. However, they are 
usually more than that because they also reflect the quality of the data, the accuracy of the statistical analysis, how convincing its interpretation is, and maybe just the intuition of the users. Generally speaking, CFs represent a subjective probability, or 'guesstimate', rather than probability based on frequencies. When there are not enough data, subjective probability is better than no estimate at all and it is usually very accurate. In fields like medicine, it has been shown that subjective expert assessments are remarkably close to the real numbers when they are compared (Sioshansi, 1983).

It should be noted, that the problem of choosing confidence factors in the current version of CESNA is made somewhat easier by the fact that only the prediction of the sign of climatic anomalies, rather than their absolute values, is sought. Therefore, the most important factor for CESNA is the consistency of the confidence factors across the knowledge base. As has been noted in the interviews with climate experts, different experts often assign very different confidence factors to the same rules, but they nevertheless remain constant in evaluating the relative importance of various rules. In other words, the system is not overly sensitive to the exact number assigned subjectively by an expert.

Another problem that is common not only for the ES-based approach, but for any other multivariate statistical methods, is the problem of mutual interdependency between climatic variables. Many early system designers found themselves caught between the unrealistic assumption of universal independence and the intractable assumption of universal interdependence. It is particularly difficult to overcome this problem in probability based systems when the number of probability assessments required can quickly become intractable (Heckerman and Nathwani, 1992).

Working with CESNA, the authors found that what is important is not an independence between climatic variables but independence of sources of information. Suppose you have two rules:

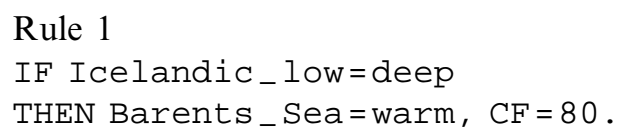

Rule 2

IF westerlies=strong

THEN Barents_Sea=warm, $\mathrm{CF}=75$.

Since variation in the central pressure of the Icelandic low is highly correlated with the strength of the midlatitude westerlies, you have to take this fact into account and somehow combine these two rules in order to avoid overestimation of Barents Sea temperature. However, if the information about the westerlies is derived from their relationship with solar activity, and the information about central pressure in the Icelandic low comes from statistical analysis of its time series, one may wish to use both these rules.

In this example, the rules reflect a physical effect of the Icelandic low and westerly winds on SST in the Barents Sea through the advection of warm Atlantic air. In many other cases, the relationships between macroclimatic variables are too complex to label cause and effect. But does this really matter in forecasting systems? In CESNA, all the rules are good until they carry information that helps to establish the value of the predictand. Thus, SST anomalies in the Barents may serve as an indicator of the state of the Icelandic low and westerlies, and if you predict one of these atmospheric variables, you need to use the information from the Barents Sea too. From this point of view, CESNA is an informational rather than physical model of the climate system.

\section{REAL-TIME FORECASTS FOR THE WINTERS OF 1995-1996, 1996-1997 AND 1997-1998}

In previous publications, the authors described experimental forecasts of winter climatic conditions produced by CESNA for three different regions: the Northwest Atlantic, European Arctic and south-eastern US (Rodionov and Martin, 1996a,b). The forecasts were given 1 year in advance for the period 1965-1995. To calculate the skill score (SS), they used the Heidke formula: 


$$
\mathrm{SS}=(H-E) /(T-E)
$$

where $H$ is the number of hits, or correct forecasts, which in this case is when the sign of temperature and index anomalies coincide; $E$ is the number of hits expected by chance; and $T$ is the total number of forecasts. The highest skill score was for the Northwest Atlantic $(\mathrm{SS}=0.65)$, but since there is a strong trend in temperature fluctuations in this region, SS is the same as what is expected based on persistence. The skill score for the European Arctic seas and south-eastern US was 0.60 and 0.54, respectively, which significantly outperformed persistence. As an example, Figure 5 illustrates the forecasts for the European Arctic seas compared with sea temperature fluctuations on the Kola Section (Barents Sea), which is considered an excellent indicator of thermal conditions for the entire region.

The forecasts for the 1965-1995 period were actually hindcasts (since the forecasting values were already known by the time of the forecast), and thus, cannot fully characterize the forecasting ability of the method. Here the real-time forecasts for the winters of 1995-1996, 1996-1997 and 1997-1998 will be discussed. These forecasts were made in the springs of 1995, 1996 and 1997, respectively, i.e. with 7-9 months lead time, and their summary is presented in Figure 6. For the sake of brevity, the whole line of reasoning used by CESNA will not be discussed here and only some extractions from the report prepared by the system will be presented.

\subsection{Winter 1995-96}

6.1.1. Forecast. In March 1995, when the forecast was prepared, it was not clear what processes were developing in the equatorial Pacific. More specifically, it was not clear whether they would result in an El Niño or La Nina event. Some indices were characteristic of a warm ENSO event, while others for a cold event. For example, solar activity was low and the gradient of sunspot numbers was negative, a situation favorable for a warm ENSO event (Mendoza et al., 1991). In addition, positive temperature anomalies were observed in the western equatorial Pacific in 1994. According to the Wyrtki hypothesis (Wyrtki, 1985), this is a precursor of a warm ENSO event in the eastern equatorial Pacific.

In contrast, both statistical prediction techniques used by the Climate Prediction Center (CCA and linear inverse modelling) indicated a gradual decrease in SST anomalies with near-normal temperatures or slightly below-normal temperatures by the end of 1995 . The coupled model predictions indicated very little change in the pattern of SST anomalies during the next 9 months. Taking into account these predictions and the indications by most atmospheric and oceanic indices, CESNA concluded that both warm and cold ENSO events had almost equal chance to occur in 1995. The confidence factors for them were small indicating near-normal conditions.

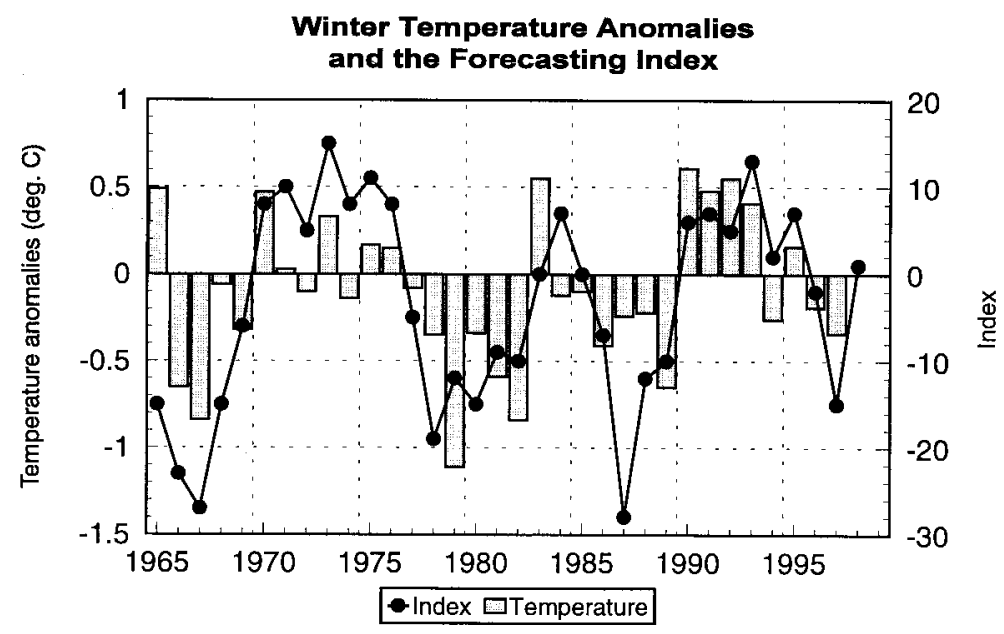

Figure 5. Mean winter (DJF) temperature in the upper 200-m layer of the Kola Section in the Barents Sea (1965-1997) and its forecast 1 year in advance. The forecasting index represent the difference between the confidence factors for warm and cold gradations 

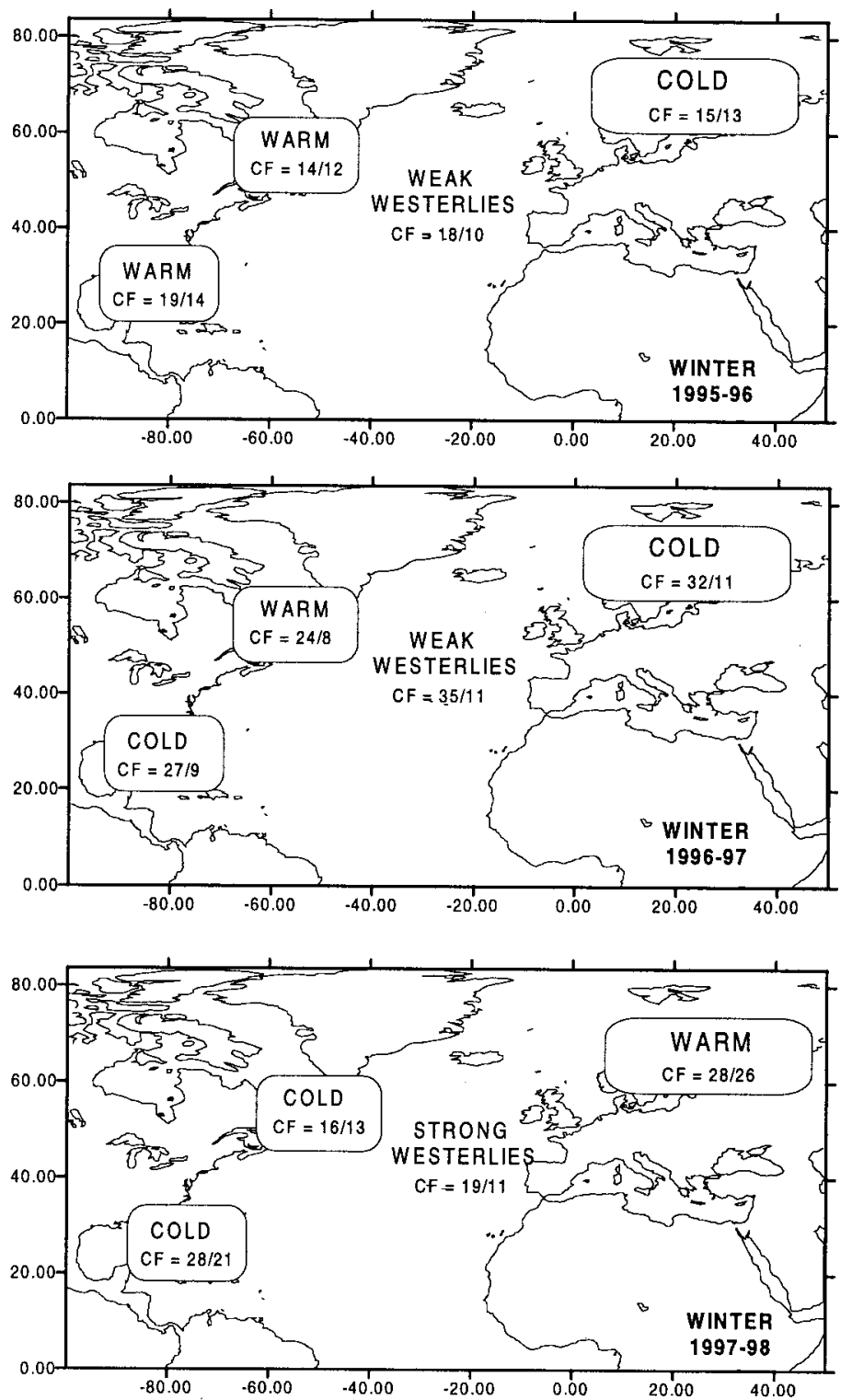

Figure 6. Experimental real-time forecasts made by CESNA for the winters of 1995-1996, 1996-1997 and 1997-1998. For each region the $\mathrm{CF}$ associated with the forecast is shown first followed by the $\mathrm{CF}$ of the alternative category

In the NH extratropics, there was also a mixed signal regarding the type of atmospheric circulation that was going to develop by the winter of 1995-1996. More factors, however, indicated that meridional rather than zonal circulation patterns would prevail. One of those factors was a low level of solar activity that was expected in 1996 due to the 11-year solar cycle in sunspot numbers. As noted by Lamb (1972), the atmospheric circulation tends to weaken around sunspot minima. He also found some evidence supportive of the hypothesis that the maximum frequency of meridional circulation patterns at the surface over Europe tends to occur when the equatorial stratospheric wind at $30 \mathrm{mb}$ level changes from west to east, a situation that was predicted to occur in the winter of 1995-1996. A strong quasi-biennial cycle in the stratospheric wind allows us to predict its fluctuations with a significant degree of confidence 1 year in advance. 
A meridional-type of atmospheric circulation over the North Atlantic sector is typically accompanied by positive temperature anomalies in the Northwest Atlantic and negative temperature anomalies in Northwest Europe and European Arctic seas (negative phase of the NAO). Nevertheless, the forecast for these regions was 'near-normal', since other factors counterbalanced the effect of the westerlies. Thus, the analysis of a 4-year cycle of SST in the Labrador Sea, and 3-, 5- and 11-year cycles of SST of the Barents Sea showed that it might be colder than normal on the west and warmer than normal on the east of the northern North Atlantic (positive phase of the NAO).

Another piece of information that suggested a possible development of a positive phase of the NAO, came from the forecast of winter conditions in the contiguous United States prepared by the Climate Prediction Center. According to this forecast, the south-eastern part of the US was supposed to be warmer than normal in the winter of 1995-1996. As shown by Barnston and He (1996), there is a strong positive relationship between winter temperature anomalies in the south-eastern US and the NAO index. The CPC forecast was put into the CESNA with a significant weight, but unfortunately, it failed (van den Dool et al., 1996). As a result, CESNA's forecast for the south-eastern US failed as well. If the CPC forecast was not taken into account, CESNA's forecast would have been 'cold' $(\mathrm{CF}=14 / 10)$ for the south-eastern US, and 'cold' $(\mathrm{CF}=15 / 7)$ for Northwest Europe.

6.1.2. Observations. In general, the winter of 1995-1996 was colder and longer than normal on the east coast of the US. It was also a winter of unusual extremes when extremely cold conditions (such as early February) were often followed by unusual warmth. The most notable cold events were the 'Blizzard of 1996', which occurred during early January 1996, and the major cold air outbreak during late Januaryearly February. Interestingly, this cold air outbreak was followed by much milder air that moved into the central and eastern US during February 6-10. During this 5-day period, temperatures in the Plains reached $21^{\circ} \mathrm{C}$ at many locations, nearly $38^{\circ} \mathrm{C}$ higher than the record low readings observed the week before at some locations.

As predicted by CESNA, during the 1995-1996 winter, the atmospheric circulation was dominated by above-normal geopotential heights over the high latitudes and by below-normal heights over the middle latitudes of the North Atlantic, so that the westerlies were weaker than normal. This flow pattern reflected a marked southward shift of the normal Atlantic jet stream and storm track, and resulted in abnormal temperature patterns in Europe. The largest negative temperature departures $\left(-2\right.$ to $\left.-4^{\circ} \mathrm{C}\right)$ were observed across northern Europe in December 1995 and February 1996. January 1996, however, was warm, particularly in Scandinavia and European Arctic seas. As a result, mean winter temperature anomalies in this region were not strongly negative. On the Kola Section of the Barents Sea, for example, temperature anomaly was $-0.2^{\circ} \mathrm{C}$ (Figure 5), which is less than half of its standard deviation.

\subsection{Winter 1996-1997}

6.2.1. Forecast. During the time of preparation of this forecast (March, 1996), all atmospheric and oceanic anomaly patterns in the region of the tropical Pacific indicated the presence of weak to moderate cold episode conditions. The southern oscillation index (SOI), however, was displaying considerable month-to-month variability and was not consistent with the other tropical indices in indicating a cold episode. CESNA's analysis of different ENSO indices as well as global distributions of precipitation and SST anomalies during the winter 1995-1996 and previous two seasons showed that no strong ENSO event would be developed later in 1996, while the distribution of SAT anomalies was slightly more characteristic of a La Niña, than El Niño situation. Particularly interesting was the distribution of SST in the Pacific Ocean. Typically, there is a strong tendency for below normal SST in the eastern tropical Pacific during summer and autumn seasons before El Niño accompanied by the same sign SST anomalies along the west coast of North America (Kiladis and Diaz, 1989). During the second half of 1995 there was a persistent negative SST anomaly in the tropical latitudes, east of the date line, whereas waters along the North American seaboard were anomalously warm.

According to the forecast issued by the CPC, the cold episode conditions developed in the equatorial Pacific were likely to continue for the next few months. However, the long-term outlook was unclear due to the considerable variability between statistical and numerical model predictions used by the CPC. 
In situations like this, when no strong ENSO event is expected, the relative importance of climatic processes in the NH extratropics itself increases. In the North Pacific, CESNA predicted that the SST pattern, established during the winter of 1995-1996, with positive anomalies along the North American seaboard and negative anomalies farther to the west, would continue to the next winter. These expectations were partly based on a statistical relationship between solar activity and water temperature in the Gulf of Alaska found by Favorite and Ingraham (1976). They have showed that when solar activity is low (as was predicted for 1997), transport of warm Pacific surface waters into the Gulf of Alaska increases. A warmer than normal temperature in the Gulf of Alaska was also expected due to extrapolation of temperature conditions based on the 18.6-year nodal cycle (Royer, 1993). This SST anomaly distribution is conducive to a meridional atmospheric circulation pattern over the Pacific/North American sector with a strong upper ridge over the Rocky Mountains and anomalously deep trough downstream. An increased advection of Arctic air along the western flank of this trough brings cold winters to the south-eastern US.

Another line of reasoning that led to the colder than normal temperature forecast for the south-eastern US involved climatic processes in the North Atlantic. A sign of SAT anomalies in the south-eastern US usually coincide with that of SST anomalies in the adjacent waters (Dickson and Namias, 1976). In the winter of 1996-1997, the latter was expected to be negative, because sea ice area concentration anomalies in the Davis Strait/Labrador Sea region in the winter of 1995-1996 were negative (unfortunately, only indirect evidence of this was available). The rule used here is based on the relationship established by Deser and Blackmon (1993).

The forecast of a cold winter in the south-eastern US was consistent with the projected weakening of the midlatitude westerlies and establishing of the negative phase of the NAO. These changes in the atmospheric circulation were predicted because the winter of 1996-1997 was expected to be the time when the minimum of solar activity would coincide with the east phase of stratospheric winds over the equator. In these years, the circumpolar vortex tends to be weaker than normal and the midlatitude westerlies become less vigorous (Labitzke and van Loon, 1988). Several other factors, such as weaker than normal Icelandic low (a prediction based on the time series analysis of its central pressure) and increased blocking activity in the Northeast Atlantic (positively correlated with strength of the upper atmospheric trough over the North American east coast) also indicated a predominance of the meridional circulation pattern in the winter of 1996-1997. These changes in the atmospheric circulation are usually associated with light ice conditions and mild winters in the Davis Strait/Labrador Sea area and cold winters in the European Arctic seas and Northwest Europe.

6.2.2. Observations. Right in line with the forecast, atmospheric circulation during the winter of 1996-1997 was characterized by a substantial blocking activity across the high latitudes and reduced westerlies over the middle latitudes. This winter, however, was not homogeneous and atmospheric circulation (as well as other characteristics) in December and January was significantly different from that in February. The prominent circulation anomalies during December and January included above-normal $500 \mathrm{hPa}$ heights over the high latitudes of the North Atlantic and below-normal heights to the south of it as well as over western Europe. These anomalies reflected a nearly complete elimination of the climatological mean jet stream over the North Atlantic, along with a very strong split-flow configuration over the central North Atlantic, and enhanced westerlies across southern Europe and north-western Africa. Overall, these conditions were typical for a negative phase of the NAO.

In February, the atmospheric circulation was in marked contrast to that observed during December and January. These changes reflected a transition to the strong positive phase of the NAO, featuring strong negative height anomalies over the high latitudes in the North Atlantic. This overall pattern reflected a complete disappearance of high latitude blocking, strengthening and eastward extension of the North Atlantic jet stream, and resulted in enhanced westerlies extending well into northern Europe.

Despite this abrupt reversal of atmospheric circulation in February that brought unseasonably warm weather to northern Europe and European Arctic seas, the mean winter temperatures in this region were below normal due to abnormally cold conditions during December and January. Some portions of 
north-eastern Europe recorded one of their coldest Decembers on record. These conditions reflected reduced onshore flow throughout the region, along with periods of enhanced cold advection associated with the high latitude blocking activity. The overall temperature anomaly pattern in Europe was similar to that of 1995-1996, a period which was also dominated by the strong negative phase of the NAO.

Unfortunately, the forecast for the south-eastern US failed. Instead of colder than normal temperatures predicted by CESNA, this region experienced an abnormally mild winter. This was very surprising because during the negative phase of the NAO, one usually observes cold winters both in northern Europe and the south-eastern US. One of the reasons for this discrepancy probably lies in the distribution of SST anomalies in the North Pacific and North Atlantic that control the position of the upper atmospheric ridge-trough system over North America. When SST anomalies are negative in the east-central North Pacific, positive along the west coast and again, negative off the southeast coast of the US, this situation is conducive to the positive phase of the PNA. The distribution of SST anomalies in December 1996 was not quite similar to that, particularly along the west coast, where near-normal temperatures were observed. It was a hope that the positive temperature anomaly with the center at $40^{\circ} \mathrm{N}, 135^{\circ} \mathrm{W}$ would move closer to the coast and this would result in an amplification of the ridge-trough system. In fact, positive SST anomalies along the North American west coast were seen (but not in the Gulf of Alaska) in January and February. By this time, however, the negative temperature anomaly off the southeast coast of the US started to disappear and, finally, was replaced by a positive SST anomaly, which probably suppressed the formation of a deep upper atmospheric trough over the east coast.

Whether or not La Niña had an effect on the SST distribution and atmospheric circulation over the Pacific/North American sector is not clear. The SOI was moderately high compared with normal but it was the first noticeable cold event since 1988. During the last two decades there was a marked shift toward more frequent warm ENSO events (Trenberth and Hurrell, 1994). With this background, the effect of the moderate 1996 La Niña may be quite significant.

\subsection{Winter 1997-1998}

6.3.1. Forecast. Unlike the previous 2 years, the situation developed by the spring of 1997 more certainly indicated that a warm ENSO event was likely to develop later this year. For example, a global distribution of SAT anomalies in the winter of 1996-1997, particularly over North America where a strip of below normal temperature stretched from north-western Canada to the central US, was very typical for the winters prior to El Niño. In addition, most of the statistical and coupled model predictions used at the Climate Prediction Center also indicated a warming trend over the next several seasons.

While the response of winter surface air temperature anomalies in the North American region to El Niño varies considerably from one event to another, there is a tendency for anomalously low temperatures in the south-eastern US to occur during the mature phase of El Niño (Ropelewski and Halpert, 1986). The ENSO effect on temperature in the south-eastern US can be modulated by the stratospheric QBO (Barnston et al., 1991). El Niño years tend to have a positive PNA projection if they have a west QBO phase, whereas this does not appear to hold true for east QBO phase years. If the QBO modulates the ENSO-climate association in the observed quasi--linear manner, anomalously warm central tropical Pacific SST plus a west QBO phase, which was expected in the winter of 1998, may favor a positive PNA circulation with higher certainty. A typical sea surface temperature (SST) distribution in the North Pacific during the years of a high PNA index is negative SST anomalies in the central North Pacific and positive SST anomalies along the west coast of North America with the extension all the way into the Gulf of Alaska. In the winter of 1996-1997, a build-up of warm temperature anomalies along the west coast was already observed. This SST pattern will likely continue to develop in 1997 and will be observed next winter as well.

The climatic situation described above is characteristic of cold winter conditions in the south-eastern US. There is, however, another line of reasoning used by CESNA according to which positive temperature anomalies may be observed in this region next winter. One of the major components of this line of reasoning is a forecasting rule proposed by Labitzke and van Loon (1988, 1993): when the sun is 
quiescent, and the stratosphere is in the west phase, the pressure will be abnormally low over North America and high over the adjacent oceans. Such anomalous pressure distribution produces warm southerly winds flowing up from the Gulf of Mexico, so that one should expect to see mild winters on the east coast. This rule worked quite well during most of the 1965-1987 period considered by Labitzke and van Loon, but failed during the real forecast experiments to predict winters of 1989 and 1991, thus reducing confidence in this rule. The overall conclusion made by CESNA for the south-eastern US was near or somewhat colder than normal.

A combination of the west phase of stratospheric winds over the Equator and relatively low solar activity will also likely to be favorable to increased cyclonic activity over the North Atlantic and strong westerly winds over its midlatitudinal belt (Labitzke and van Loon, 1988, 1993). Some other rules reinforce this expectation. One of them is based on a positive statistical relationship between sunspot numbers and frequency of blocking situations in the Northeast Atlantic (Lamb, 1972; Baidal and Neushkin, 1992). Another rule takes into account quasi-periodic behavior of central pressure in the Icelandic low (Angell et al., 1969). While a forecast based on these cycles is not very reliable by itself, it adds some confidence to stronger than normal westerlies in 1998.

It will be necessary to closely watch solar activity this year. It enters into the ascending phase of its 11-year cycle, and if it increases significantly compared with the previous year, one may see meridional circulation patterns more frequently (Lamb, 1972; Girskaya et al., 1987). As found by Shirley (1988), during the entire period of 1992-2000, meridional circulation is more likely to occur than zonal circulation. Overall, however, the confidence factor for the zonal circulation was somewhat higher than that for the meridional circulation in the North Atlantic.

Due to the expected predominance of a positive phase of the NAO, the forecast for Northwest Europe and European Arctic seas was near or somewhat warmer than normal, and for the Northwest Atlantic was near, or colder than normal. The closeness of the forecast to normal was not because factors affecting temperature in these regions will be near their normal values, but because these factors will counterbalance each other. For example, strong westerlies over the North Atlantic and positive temperature anomalies in Northwest Europe due to the effect of solar activity and QBO may be offset by the effect of strong El Niño on atmospheric circulation and temperature in Europe (Fraedrich and Muller, 1992). Therefore, there may be periods during next winter when one of the factors will become dominant and bring forth significant anomalies of one or another sign. As a result, one may see enhanced intraseasonal variations in temperature and other climatic variables.

One of the most difficult questions during this forecast was whether or not a transition from one climatic regime to another was being observed. If the mean winter sea temperature on the Kola Section of the Barents Sea (Figure 5) are looked at, it can be observed that during the period from 1977 to 1989 all the winters except that of 1982-1983 were colder than normal. On contrast, the winters from 1989-1990 to 1992-1993 were very mild. If the air temperature at meteorological stations in Norway and northern Russia (not shown) are considered, the dates for these cold and warm regimes vary somewhat, but it can still be said that the late 1970s and most of the 1980s were cold, while the late 1980s and the first half of the 1990s were predominantly warm. During the last 2 years there were some indications of a transition toward a new cold regime in the European Arctic Seas and northern Europe; thus despite a strong intraseasonal variability in both the winter 1995-1996 and the winter of 1996-1997 being cold. A substantial rearrangement of the Atlantic Ocean SST features in the mid-1990s was also noticed by Gray (1996).

The same is true for other regions of the Northern Hemisphere, such as the Bering Sea. Temperature fluctuations in the Bering Sea are mostly out-of-phase with those in the Barents Sea (Rodionov and Krovnin, 1991) while in the last years this relationship was corrupted to some extent. Nevertheless, by the middle of the 1990s ice cover in the Bering Sea significantly increased compared with the 1980s and early 1990s, when below-normal ice cover was observed. What is also important is that, as one analysis made in the Russian Federal Institute of Marine Fisheries and Oceanography (VNIRO) has shown (A. Krovnin, personal communication), the relationship between ice cover in the Bering Sea and the 11-year solar cycle seems to have been restored, and beginning with 1998, they expect a new phase of this cycle with below-normal ice cover. 
The south-eastern US is another region where temperature regimes are well-pronounced (Dickson and Namias, 1976) and by and large coincide with those in the European Arctic Seas. The late 1980s and, particularly, the first half of the 1990s were very warm in the south-eastern US and on the east US coast in general. In the middle of the 1990s, mean winter temperatures in this region decreased to their normal values, and the winter of 1995-1996 was cold. As noted above, the winter of 1996-1997 was unusually warm and, strangely enough, it was accompanied by a cold winter in the European Arctic Seas. This actually most often happens during the transition from one regime to another. Therefore, it is possible that beginning with, if not the winter of 1997-1998, then the winter of 1998-1999, we can see a time spell of cold winters both in the south-eastern US and Northwest Europe.

6.3.2. Observations. The winter of 1997-1998 passed under the influence of El Niño, one of the strongest (and, according to some indices, the strongest) events of the century. During El Niño events, especially if they are accompanied by positive SST anomalies along the west coast of North America, atmospheric circulation is usually characterized by positive PNA pattern and negative temperature anomalies in the south-eastern US (Ropelewski and Halpert, 1986). Thus, in 30 out of 41 winters in this century when waters along the west coast were warm, temperatures in the south-eastern US were below normal. The winter of 1997-1998, however, despite the positive PNA index, was near normal in this region. It does not mean that temperature remained near its normal value throughout the winter. On the contrary, its intraseasonal variability was very high, with strong negative anomalies in December 1997 and positive anomalies in January 1998 that canceled each other out. As the authors suggested in the forecast, this might be a result of two conflicting forces, one related to El Niño and the other to a combined effect of solar activity and stratospheric QBO.

Atmospheric circulation over the North Atlantic in the winter of 1997-1998 was very unusual. It is very difficult to classify it as either positive or negative phase of the NAO. The Icelandic low was deep and shifted northeast toward the Norwegian Sea. At the same time, cyclonic activity was also increased in the subtropical latitudes. This anomalous atmospheric circulation at the surface was a reflection of a complete separation of the polar and subtropical jet streams aloft. The former was located along approximately $60^{\circ} \mathrm{N}$, while the latter was at about $25^{\circ} \mathrm{N}$. Such a significant distance between the polar and subtropical jet streams is very atypical for the winter months and is rarely observed on mean monthly maps. Normally, there is a single jet core extending northeastward across the North Atlantic from the mid-Atlantic region of the US to northern UK.

As predicted, the Northwest Atlantic was colder than normal and northern Europe and adjacent waters were generally warmer than normal. It is important to note, however, that the distribution of temperature anomalies within the latter region was extremely inhomogeneous. Thus, while the winter in Scandinavia and the Norwegian Sea was extremely mild, the winter in northern Russia and the Barents Sea was abnormally cold.

\section{CONCLUSION}

The approach described in this article is empirical in nature. Predictions are based on a co-ordinated use of production IF-THEN rules that reveal expected correlations between macroclimatic variables. This approach quantifies the authors experience-based expectations and provides estimates of forecast uncertainty. It can also provide diagnostic information about climatic dynamics, and is much less expensive than approaches based on high-resolution numerical models.

The authors' work with CESNA has shown that it is an excellent organizational tool that can easily combine various (even contradictory) evidence and ideas regarding large-scale interactions in the ocean-atmosphere-land system and arrange them in a way to make a forecast of interannual climatic variations possible. It can also easily incorporate the results of other forecasting methods such as those used in the CPC. It is important that, unlike other approaches, CESNA clearly explains why it came to this or that conclusion. CESNA is designed first of all as an intelligent assistant to a researcher that 
facilitates analysis, diagnosis and predictions of short-term climatic fluctuations. In addition, since it can be used by policy-makers who have enough training in climatology, it can also be considered as a decision support system.

The predictive capabilities of CESNA were tested on both hindcasts and real-time forecasts for the winters 1995-1996 through 1997-1998. These winters were very difficult to predict. The first two were characterized by extremely strong intraseasonal variations and the last one was the winter of an El Niño event of exceptional scale. There is some evidence that these years may be transitional from the climatic regime of the late 1980s and first half of the 1990s to a new regime with substantially opposite characteristics, such as weaker than normal westerlies over the North Atlantic and colder than normal winters in north-western Europe. However, even in these circumstances, CESNA has revealed definite skill in predicting predominant types of atmospheric circulation over the North Atlantic and temperature anomalies in the Northwest Atlantic and northern European region.

The forecasts were less successful for the south-eastern US. One obvious failure was the forecast for winter 1996-1997. Instead of predicted cold winter, it happened to be mild, which was not typical for the winters with negative phase of the NAO. The reason for this failure lies in a poor understanding of the mechanism that control intensity and meridional position of the upper atmospheric trough over the east North American coast. In some years it may be shifted too far east or west from its predominant position during periods of meridional atmospheric circulation, and this makes a significant difference for such sensitive areas as the south-eastern US.

This example clearly shows that there is a need to know more about the origin of monthly and seasonal climatic anomalies and those mechanisms that control them, if it is to be possible to accurately predict climatic variations from year to year. But the advantage of CESNA compared with conventional forecasting methods is that its knowledge base can be easily updated or modified to reflect new findings and ideas. Moreover, CESNA highlights those areas where further research is most needed.

In conclusion, the authors say that CESNA increased their confidence that the climate system (presented as a set of macroclimatic objects) has some aspects that are predictable a year or more in advance. Experimental forecasts have shown that it is important to collect as many rules as possible describing all the major components of the climate system and the effect of external factors, even at the expense of a simplification of this description. Of course, there is no guarantee that a relationship that worked well in the past will work in the future. But the hope is that by piecing together bits of historical evidence from many different sources and areas of the world, one can create a necessary 'critical mass' of rules, so that even some of them fail, the remaining rules collectively lead to the correct result.

\section{ACKNOWLEDGEMENTS}

The work is supported by the National Science Foundation under Grant ATM-9320455 and a generous gift from the Mars Company.

\section{REFERENCES}

Alexander, M.A. and Weickmann, K.M. 1995. 'Biennial variability in an atmospheric general circulation model', J. Clim. Boston, 8, 431-440.

Angell, J.K., Korshover, J. and Gotton, G.F. 1969. 'Quasi-biennial variations in the 'centers of action', Mon. Weather Rev., 97, 867-872.

Arkin, P.A. 1993. 'Operational seasonal prediction at NMC', in Shukla, J. (ed.), Prediction of Interannual Climate Variations, Springer, Berlin, pp. 183-195.

Baidal, M.H. and Neushkin, A.I. 1992. Thermodynamic Regime and Contingency of Northern Atlantic's Atmospheric Circulation and Weather, Printer Publishers, Obninsk, Russia.

Barnston, A.G. 1994. 'Linear statistical short-term climate predictive skill in the Northern Hemisphere', J. Clim., 5, $1514-1564$.

Barnston, A.G. and He, Y. 1996. 'Impacts of the NAO on US and Canadian surface climate; Implications for seasonal predictions'. Proc. 21st Ann. Clim. Diagn. Pred. Workshop, October 28-November 1, 1996, Hunstsville, AL, pp. $34-37$.

Barnston, A.G. and Livezey, R.E. 1987. 'Classification, seasonality and persistence of low-frequency atmospheric circulation patterns', Month. Weather Rev., 115, 1083-1126.

Barnston, A.G. and Ropelewski, C.F. 1992. 'Prediction of ENSO episodes using canonical correlation analysis', J. Clim., 5, 1316-1345. 
Barnston, A.G., Livezey, R.E. and Halpert, M.S. 1991. 'Modulation of southern oscillation-northern hemisphere midwinter climate relationships by the QBO', J. Clim., 4, 203-217.

Barnston, A.G., van den Dool, H.M., Zebiak, S.E., Barnett, T.P., Ji, M., Rodenhuis, D.R., Cane, M.A., Leetmaa, A., Graham, N.E., Ropelewski, C.R., Kousky, V.E., O'Lenic, E.A. and Livezey, R.E. 1994. 'Long-lead seasonal forecasts-where do we stand?' Bull. Am. Meteorol. Soc., 75, 2097-2114.

Barnston, A.G., Thiao, W. and Kumar, V. 1996. 'Long-lead forecasts of seasonal precipitation in Africa using CCA', Weather Forecasting, 11, 506-520.

Bradley, R.S., Diaz, H.F. Kiladis, G.N. and Eischeid, J.K. 1987. 'ENSO signal in continental temperature and precipitation records', Nature, 327, 497-501.

Bucha, V. 1991. 'Solar and geomagnetic variability and changes of weather and climate', J. Atmos. Terr. Phys., 53, $1161-1172$.

Buchanan, B.G. and Shortliffe, E.M. 1984. Rule-Based Expert Systems, Addison-Wesley, Reading, MA.

Burroughs, W.J. 1992. Weather Cycles, Real or Imaginary?, Cambridge University Press, Cambridge.

Cane, M.A., Zebiak, S.E. and Dolan, S.C. 1986. 'Experimental forecasts of El Niño', Nature (London) 321, $827-832$.

Chen, D., Zebiak, S.E., Busalacchi, A.J. and Cane, M.A. 1995. 'An improved procedure for El Niño forecasting: implications for predictability', Science, 269, 1699-1702.

Colman, A. and Davey, M. 1997. 'Linear regression forecast of central England temperature for July-August 1997', Exp. Long-Lead Forecast Bull., 6(2), 43-45.

Conway, B.J. 1989. 'Expert systems and weather forecasting', Meteorol. Mag., 118, 23-30.

Dantzler, H.L and Scheerer, D.J. 1993. An Expert System for Describing and Predicting the Coastal Ocean Environment, John Hopkins APL Tech. Digest, 14, 181-192.

Davis, R.E. 1978. 'Predictability of sea level pressure anomalies over the North Pacific', J. Phys. Oceanogr., 8, $233-246$.

Deser, C. and Blackmon, M.L. 1993. 'Surface climate variations over the North Atlantic during winter: 1900-1989', J. Clim., 6, $743-756$.

Dickson, R.R. 1988. 'Great salinity anomaly in the northern North Atlantic, 1968-1987', Prog. Oceanogr., 20, $103-151$.

Dickson, R.R. and Namias, J. 1976. 'North American influences on the circulation and climate of the North Atlantic sector', Month. Weather Rev., 104, 1255-1265.

Douglas, A.V., Cayan, D.R. and Namias, J. 1982. 'Large-scale changes in North Pacific and North American weather patterns in recent decades', Month. Weather Rev., 110, 1852-1862.

Elsner, J.B. and Schmertmann, C.P. 1993. 'Improving extended-range seasonal predictions of intense Atlantic hurricane activity', Weather Forecasting, 8, 345-351.

Enfield, D.B. and Cid, S.L. 1991. 'Low-frequency changes in El Niño-southern oscillation', J. Clim., 4, $1137-1146$.

Favorite, F. and Ingraham, W.J. Jr. 1976. 'Sunspot activity and oceanic conditions in the northern North Pacific Ocean', Oceanogr. Soc. Jpn., 32, 107-115.

Favorite, F. and McLain, D.R. 1973. 'Coherence in trans-Pacific movements of positive and negative anomalies of sea surface temperature', Nature, 244, 139-143.

Fraedrich, K. and K. Muller, K. 1992. 'Climate anomalies in Europe associated with ENSO extremes', Int. J. Climatol., 12, 25-31.

Glenn, S.M., Forristal, G.Z., Cornillon, P. and Milkowski, G. 1990. 'Observations of Gulf Stream ring 83-E and their interpretation using feature models', J. Geophys. Res., 95, 13043-63.

Girskaya, A.I., Loginov, V.F. and Sazonov, B.I. 1987. 'Droughts and severe winters in the Northern Hemisphere and solar activity', Trudy $G G O, \mathbf{5 1 3}, 144-149$.

Gopal, S. and Scuderi, L. 1995. 'Application of artificial neural networks in climatology: a case study of sunspot prediction and solar climate trends', Geogr. Anal., 27, 42-55.

Gray, W.M. 1996. 'Forecast of global circulation characteristics in the next 25-30 years', Proc. 21st Ann. Clim. Diagn. Pred. Workshop, October 28-November 1, 1996, Hunstsville, AL, pp. 219-222.

Gray, W.M. and Sheaffer, J.D. 1991. 'El Niño and QBO influences on tropical cyclone activity', in M.H. Glantz et al. (eds.), Teleconnections Linking Worldwide Climate Anomalies, Cambridge University Press, Cambridge, pp. 257-284.

Gray, W.M., Landsea, C.W., Mielke Jr, P.W., Berry, K.J. and Knaff, J.A. 1996. 'Our evolving methodology and philosophy for the prediction of Atlantic basin seasonal hurricane activity', Proceedings of the 21st Annual Climate Diagnosis and Prediction Workshop, October 28-November 1, 1996, Huntsville, Alabama, 38-41.

Heckerman, D.E. and Nathwani, B.N. 1992. 'Toward normative expert systems, Part II: Probability-based representations for efficient knowledge acquisition and inference', Methods Inform. Med., 31, 106-114.

Huang, J., van den Dool, H.M. and Barnston, A.G. 1996. 'Long-lead seasonal temperature prediction using optimal climate normals', J. Clim., 9, 809-817.

Hushon, J.M. (ed.) 1990. Expert Systems for Environmental Applications, American Chemical Society, Washington, DC.

Ji, M.A., Kumar, A. and Leetmaa, A. 1994. 'An experimental coupled forecast system at the National Meteorological Center, some early results', Tellus, 46A, 398-418.

Kerr, R.A. 1992. 'A successful forecast of an El Niño winter', Science, 255, 403.

Kiladis, G.N. and Diaz, H.F. 1989. 'Global climatic anomalies associated with extremes in the southern oscillation', J. Clim., 2, 1069-1090.

Kiladis, G.N., and van Loon, H. 1988. 'The southern oscillation, Part VII: Meteorological anomalies over the Indian and Pacific sectors associated with the extremes of the oscillation', Month. Weather Rev., 116, 120-136.

Kumar, V.R., Chung, C.Y.C. and Lindley, C.A. 1994. 'Toward building an expert system for weather forecasting operations', Expert Syst. Appl., 7, 373-381.

Labitzke, K. and van Loon, H. 1988. 'Association between the 11-year solar cycle, the OBO and the atmosphere, Part 2. Surface, 700 mb', J. Clim., 1, 905-920.

Labitzke, K. and van Loon, H. 1993. 'Some recent studies of probable connections between solar and atmospheric variability', Ann. Geophys., 11, 1084-1094.

Lamb, H.H. 1972. Climate: Present, Past and Future, Methuen, London. 
Livezey, R.E. 1990. 'Variability of skill of long-range forecasts and implications for their use and value', Bull. Am. Meteorol. Soc., 71, 300-309.

Luger, G.F. and Stubblefield, W.A. 1993. Artificial Intelligence. Structures and Strategies for Clomplex Problem Solving, The Benjamin/Cummings Publishing Company, Redford City, CA.

Mann, M.E., Lall, U. and Saltzman, B. 1995. 'Decadal-to-centennial-scale climate variability: insights into the rise and fall of the Great Salt Lake', Geophys. Res. Lett., 22, 937-940.

Marko, J.R., Fissel, D.B. Wadhams, P., Kelly, P.M. and Brown, R.D. 1994. 'Iceberg severely off eastern North America and its relationship to sea ice variability and climate change', J. Clim., 7, 1335-1351.

Mena, J. 1996. 'Automatic data mining', PC AI, November/December, pp. 16-20.

Mendoza, B., Perez-Enriquez, R. and Alvarez-Madrigal, M. 1991. 'Analysis of solar activity conditions during periods of El Niño events', Ann. Geophys., 9, 50-54.

Moninger, W.R. 1990. 'Summary report on the third workshop on artificial intelligence research in environmental science (AIRIES-89): 2-4 May 1989, Tysons Corner, VA', Bull. Am. Meteorol. Soc., 71, 672-679.

Namias, J. 1972. 'Experiments in objectively predicting some atmospheric and oceanic variables for the winter of 1971-1972', $J$. Appl. Meteorol., 110, 1164-1174.

Namias, J. 1976. 'Negative ocean feedback system over the North Pacific in the transition from warm to cold seasons', Month. Weather Rev., 104, 1107-1121.

Namias, J. 1985. 'Remarks in the potential for long-range forecasting', Bull. Am. Meteorol. Soc., 66, $165-172$.

Namias, J. and Cayan, D.R. 1981. 'Large-scale air-sea interactions and short-period climatic fluctuations', Science, 214, 869-878.

Palmer, T.N. and Anderson, D.L.T. 1994. 'The prospects for seasonal forecasting-A review paper', Q. J. R. Meteorol. Soc., 120, $755-793$

Penland, C. and Magorian, T. 1993. 'Prediction of Niño 3 sea surface temperatures using linear inverse modeling', J. Clim., 6, $1067-1076$.

Penland, C. and Matrosova, L. 1998. 'Predictions of tropical Atlantic sea surface temperatures using linear inverse modeling', $J$. Clim., 11, 483-496.

Rasmusson, E.M., Arkin, P.A. Chen, W.Y. and Jalickee, J.B. 1981. 'Biennial variations in surface temperature over the United States as revealed by singular decomposition', Month. Weather Rev., 109, 587-598.

Rodionov, S.N. 1994. Global and Regional Climate Interactions: The Caspian Sea Experience. Kluwer, Dordrecht, $241 \mathrm{pp}$.

Rodionov, S.N. and Krovnin, A.S. 1991. 'Interannual variability of thermal conditions in the Bering Sea', Proc. Int. Symp. on Bering Sea Fisheries, April 2-5, 1990, Khabarovsk, Russia, Alaska Fisheries Science Center, Seattle, WA, pp. 49-55.

Rodionov, S.N. and Krovnin, A.S. 1992. 'The 1980s in the context of climate changes in the North Atlantic region', ICES Mar. Sci. Symp., 195, 86-95.

Rodionov, S.N. and Martin, J.H. 1996a. 'A knowledge-based system for the diagnosis and prediction of short-term climatic changes in the North Atlantic', J. Clim., 9, 1816-1823.

Rodionov, S.N. and Martin, J.H. 1996b. 'Managing uncertainty in a climatic expert system', Proc. 13th Conf. on Probability and Statistics in Atmospheric Sciences, 21-23 February 1996, San Francisco, CA, USA.

Ropelewski, C.F. and Halpert, M.S. 1986. 'North American precipitation and temperature patterns associated with El Niño-southern oscillation (ENSO)', Month. Weather Rev., 114, 2352-2362.

Ropelewski, C.F. and Halpert, M.S. 1989. 'Precipitation patterns associated with the high index phase of the southern oscillation', J. Clim., 2, 268-284.

Royer, T.C. 1993. 'High-latitude oceanic variability associated with the 18.6-year nodal tide', J. Geophys. Res., 98, 4639-4644.

Semenyuk, E.A. 1984. 'The role of thermal conditions of sea surface in formation of persistence of temperature anomaly field', Trudy Vsesoyuznogo Nauchno-Issledovatel'skogo Instituta Gidrometeorologicheskoi Informatsii-Mirovoi Tsentr Dannyh (VNIIGMI-MCD) [Proceedings of the All-Union Research Institute of Hydrometeorological Information-World Data Center], vol. 117 , pp. 5-15 (in Russian).

Seryakov, E.I. 1979. Long-Term Forecasts of Thermal Processes in the North Atlantic. Gidrometeoizdat, Leningrad (in Russian).

Shabbar, A. and Barnston, A.G. 1996. 'Skill of seasonal climate forecasts in Canada using canonical correlation analysis', Month. Weather Rev., 124, 2370-2385.

Shirley, J.H. 1988. 'When the sun goes backward: solar motion, volcanic activity and climate', Cycles, 39, 113-119.

Shukla, J. 1993. 'Predictability of short-term climate variations', in Shukla, J. (ed.), Prediction of Interannual Climate Variations, Springer, Berlin, pp. 183-195.

Sioshansi, F.P. 1983. 'Subjective evaluation using expert judgement: an application', IEEE Trans. Syst. Man Cybernetics, 13, $391-397$.

Trenberth, K.E. and Shin, W.T.K. 1984. 'Quasi-biennial fluctuations in sea level pressure over the Northern Hemisphere', Month. Weather Rev., 112, 761-777.

Trenberth, K.E. and Hurrell, J.W. 1994. 'Decadal atmosphere-ocean variations in the Pacific', Clim. Dyn., 9, $303-319$.

Tucker, G.B. and Barry, R.G. 1984. 'Climate of the North Atlantic Ocean', in van Loon, H. (ed.) Climates of the Oceans, World Survey of Climatology, vol. 15, Elsvier, Amsterdam, pp. 193-157.

van den Dool, H.M., Hoopingarner, J., O’Lenic, E., Wagner, A.J., Barnston, A.G., Livezey, R.E., Unger, D., Masutani, M., Artusa, A., Huang, J. and Chirchill, R. 1996. '1st annual review of skill of CPC long-lead seasonal predictions', Proc. 21st Annu. Climate Diagnostics and Prediction Workshop, Huntsville, AL, October 28-November 1, 1996, US Department of Commerce, NOAA/ NWS, pp. 13-16.

van Loon, H. and Rogers, J.C. 1978. 'The seesaw in winter temperatures between Greenland and Northern Europe. Part I: General description', Month. Weather Rev., 106, 296-310.

Varis, O. 1995. 'Belief networks for modeling and assessment of environmental change', Environmetrics, 60, $439-444$.

Wallace, J.M. and Jiang, Q. 1992. 'On the observed structure of the interannual variability of the atmosphere/ocean climate system', in H. Cattle (ed.), Atmospheric and Oceanic Variability, Bracknell, UK, pp. 17-43. 
Ward, M.N. and Folland, C.K. 1991. 'Prediction of seasonal rainfall in the North Nordeste of Brasil using eigenvectors of sea surface temperature', Int. J. Climatol., 11, 711-743.

Wyrtki, K. 1985. 'Water displacements in the Pacific and the genesis of El Niño cycles', J. Geophys. Res., 90, 7129-7132.

Zadeh, L.A. 1965. 'Fuzzy sets', Informat. Control, 8, 338-353.

Zadeh, L.A. 1987. Fuzzy Sets and Applications: Selected Papers, Wiley, New York, NY.

Zhifang, F. and Wallace, J.M. 1993. 'The relationship between the wintertime blocking over Greenland and the sea ice distribution over North Atlantic', Adv. Atmos. Sci., 10, 453-464. 